This item was submitted to Loughborough's Research Repository by the author.

Items in Figshare are protected by copyright, with all rights reserved, unless otherwise indicated.

\title{
M.R. Haberfeld and Dale Sheehan (ed): Match-Fixing in International Sports: Existing Processes, Law Enforcement and Prevention Strategies [review]
}

PLEASE CITE THE PUBLISHED VERSION

http://dx.doi.org/10.1007/s12117-015-9243-2

\section{PUBLISHER}

(C) Springer

VERSION

AM (Accepted Manuscript)

\section{PUBLISHER STATEMENT}

This work is made available according to the conditions of the Creative Commons Attribution-NonCommercialNoDerivatives 4.0 International (CC BY-NC-ND 4.0) licence. Full details of this licence are available at: https://creativecommons.org/licenses/by-nc-nd/4.0/

\section{LICENCE}

CC BY-NC-ND 4.0

\section{REPOSITORY RECORD}

Manoli, Argyro Elisavet. 2019. "M.R. Haberfeld and Dale Sheehan (ed): Match-fixing in International Sports: Existing Processes, Law Enforcement and Prevention Strategies [review]". figshare. https://hdl.handle.net/2134/21780. 
M. R. Haberfeld and Dale Sheehan (Ed):

Match-Fixing in International Sports: Existing Processes,

Law Enforcement and Prevention Strategies

New York, N.Y.: Springer, 2014, ISBN 978-3-319-02581-0

Argyro Elisavet Manoli

Match-Fixing in International Sports, edited by Maria R. Haberfeld and Dale Sheehan, is a very informative collection on a rather under-researched but increasingly important topic. The book was compiled following the 'Integrity in Sport Meeting', an international conference that took place in November 2012 in Singapore, with the aim to create academic awareness and trigger discussion about the operationalisation of Sports Related Crimes (SRC), in order to facilitate an effective justice response globally, while underlying Academia's role within it. The fact that both the Secretary General of INTE RPOL, Ronald K. Noble, and FIFA's Head of Security, Ralf Mutschke, welcome the book draws additional attention to the need for further research on the issue of matchfixing, as the recent collaboration between the two organisations has also suggested. It worth noting that in both the Foreword and the Preface match-fixing is presented as a crime on the rise, with the emphasis drawn on the involvement of 'organised criminal organisations'.

Following the first chapter (Introduction to the collection), in which the editors provide the reader with a summary of the chapters that follow, the book is divided in three parts, each of which focuses on a different aspect of match-fixing. Due to the volume of the book, a detailed analysis for every chapter cannot be offered; however, a short overview will be attempted. . Part one includes six chapters, all evolving around the definitional and operational issues of match-fixing, predominantly in football, in a number of countries in Europe, Asia and Africa. Chapter two focuses on German football and introduces five match-fixing scandals that attracted considerable media attention, while examining the suggestions made by the 5th World Sports Ministers Conference that took place in May 2013 in Berlin. The chapter's importance lies on the long list of recommendations provided that include, but are not limited to, organisational, regulatory and legal changes in the football industry; recommendations that have a world-wide appeal.

Chapter three introduces betting and corruption in Uganda not only in football but in a number of sports. In order for the reader to comprehend the current sport landscape, the author provides information on the socio-cultural, legal and political factors that have affected not only the country but the whole region. The interesting recommendations offered at the end of the chapter include a number of regulatory and legal suggestions as well as recommendations with educational focus, a topic that is also examined later in the book. Chapter four discusses 'problematic' betting in Indian cricket, which has attracted considerable media attention. The reasons behind the increase in betting provide the reader with the background knowledge needed to understand the wider implications betting has in a number of sports in the country. Chapter five touches on football match-fixing in two European countries, Greece and Ireland. The authors introduce the structure of the leagues in both countries, while mentioning some match-fixing allegations that have attracted media attention. The current background of the football industry in both countries is discussed while underlining its weaknesses; however, few suggestions for the future of the sport are made. Chapter six provides an economic in-depth analysis of two of the most wellknown 
match-fixing scandals in professional football, Calciopoli and Sommessopoli, in order to evaluate the economic determinants of corruption in sports. The analysis explains that the two Italian scandals are dissimilar, which allows for the authors to provide some insightful recommendations for prevention.

Chapter seven introduces the current state of professional Russian football, in which match-fixing is a thriving ever ending business. The author focuses on the definitional issues of match-fixing and categorises the cases based on their operational structure and aim. As suggested, a number of legal and regulatory matters have to be addressed, in order for the future of the sport to be secured.

Part two examines the contemporary approaches to match-fixing around the globe, designed to respond to the phenomenon. Chapter eight introduces the Australian approach to safeguard the integrity of sports, through an overview of the most celebrated match-fixing cases, the key patterns behind them, and the responses to them. The chapter also suggests that since confronting match-fixing and corruption in sports became a priority for the country, the future of the sport has been painted with brighter colours, setting the milestones for other countries to follow. Chapter nine examines the economic effects betting cheating can have in sports and its various aspects, such as the influence on the overall commercialisation and the individuals' performance. The German betting market is used as the case study in order for a theoretical model to be developed, which allows for the authors to offer some potential recommendations. Chapter ten provides an economic analysis of the phenomenon of match-fixing using the supply-demand framework. This framework is used both in the examination of this increasing phenomenon and the reasons behind it, and to offer suggestions on the policies that could protect the integrity of the sport. Chapter eleven examines compliance initiatives, as well as their limitations, as part of a wider governance scheme in sport organizations for preventing sport corruption. The chapter also includes the exploration of the idea of the use of accreditation and licensing as tools to reinforce compliance initiatives and help prevent match-fixing.

Chapter twelve explores the role of academia in the prevention of match-fixing in Brazil, with emphasis placed on the lack of academic input on areas such as the Justice System in general and the Sports Justice institutions in particular. The intellectual investment needed on the topic could assist, according to the authors, in the prevention of the phenomenon in the future. Chapter thirteen provides the reader with a conceptual approach of sports-related crime, employing the Game Theory approach and the Prisoner's Dilemma in order to gain insight into the interactions and dynamics between the relevant actors. The cognitive valence map designed allows for the author to suggest some potential preventive legal strategies.

The third and final part of the book includes five chapters that focus on the future of match-fixing prevention. Chapter fourteen introduces the actions INTERPOL has taken in response to match-fixing worldwide. The INTERPOL - FIFA collaboration is also presented, with emphasis drawn on the three-pillar response, Training, Education and Prevention, aiming at increasing awareness among stakeholders. Chapter fifteen examines the role of Academia in protecting sports integrity and safeguarding the future of sports. According to the author of the chapter, educating individuals about sports ethics and the effects morality in sports can have in other aspects of the society can help in the preservation of sports. Chapter sixteen considers the role of Academia as well, however, this time against match-fixing. Education of individuals is an area in which Academia can assist, according to the author, with more emphasis drawn on research and identification of the extent and scope of the problem.

Chapter seventeen uses a well-known Turkish football scandal as a template in order 
to present the reader with the operational side or a successful police investigation. The analysis of the police operations leads into the introduction of some policy implications in order to raise awareness among the followers of the sport. Finally, chapter eighteen, the final chapter of part three and epilogue of the book, presents the reader with the reasons behind organising the Global Experts Meeting that led to the creation of this book. The role of Academia is discussed as a key element in tackling match-fixing, while a potential collaboration between INTERPOL and academia is also examined. As an overview of the book, part one provides the reader with an informative account of match-fixing cases in a number of countries, while also including possible recommendations to protect sports from such phenomena. The chapters included in this part tend to focus on practical examples and equally practical recommendations, which engage the reader, while successfully underlying the importance of tackling matchfixing. This is the most engaging and possibly the best part of the book, which also emphases the need for further research on the topic. The topics examined in part two are equally informative, but with a slight emphasis placed on theoretical examination of possible prevention suggestions, rather than actual tested solutions. The conceptual analyses included in this part are not in fact focused on current prevention methods, as the title suggests, but more on expanding the current understanding of the implications of the phenomenon. The models, frameworks and conceptual approaches included in this part enhance the reader's understanding of match-fixing but do not succeed, however, in presenting the current tested responses to the phenomenon.

Part three focuses on the future of the sport and match-fixing, but approaches it again in a more conceptual, rather than a practical way. The role of academia in tackling match-fixing is given additional emphasis, while in a rather unorthodox way, the aim of the book is better presented and explained in the final chapter of the book. Based on this aim, the collection succeeds in raising awareness on the increasingly important issue of match-fixing, while examining the role of Academia in its prevention and the safeguarding of sports. However, apart from presenting the promising collaboration of INTERPOL and FIFA, this part's emphasis is drawn on a very interesting but arguably less practical topic. As chapter ten suggests, match-fixing is a matter of supply and demand, and the part Academia can play in tackling this pragmatic supply-demand relation is yet to be discussed.

Overall, the book achieves its main purpose to raise awareness about match-fixing and its operational and economical processes around the globe. The fact that a number of countries - case studies are examined acts as both a strength and a weakness to the book. On the one hand, the spread and frequency of the phenomenon is emphasised, and even though the attention is mostly drawn on football, the applicability of the templates the case studies provide allow for their adoption and customisation for other sports. On the other hand, however, the overview provided does not allow for in-depth analysis on any of the cases, with the redundancy in the approaches (as mentioned in Chapter one) weakening the book.

That being said, Match-Fixing in International Sports is a very informative collection on a rather under-researched topic that is receiving increasing attention. The number of topics covered and the polyphony of the authors allow the reader to grasp the wide picture of this phenomenon. This book should be read by anyone interested in understanding match-fixing, the reasons behind it and its implications around the globe. 